\title{
Influenza vaccination among pregnant women in two hospitals in Sydney, NSW: what we can learn from women who decline vaccination
}

\author{
Jocelynne E McRae ${ }^{a, e}$, Aditi Deyª, Samantha Carlsonn, \\ John Sinn ${ }^{d}$, Peter McIntyre ${ }^{a}$, Frank Beard ${ }^{a}$, Kristine Macartney ${ }^{a, b}$ and \\ Nicholas Wooda,b \\ a National Centre for Immunisation Research and Surveillance, Sydney, NSW, Australia \\ b Discipline of Child and Adolescent Health, Faculty of Medicine and Health, University of Sydney, NSW, Australia \\ c Telethon Kids Institute, Perth, WA, Australia \\ d Department of Neonatology, Royal North Shore Hospital, Sydney, NSW, Australia \\ e Corresponding author: jocelynne.mcrae@health.nsw.gov.au
}

\section{Article history}

Publication date: July 2021

Citation: McRae JE, Dey A, Carlson S, Sinn J, Mclntyre P, Beard F, Macartney K, Wood N. Influenza vaccination among pregnant women in two hospitals in Sydney, NSW: what we can learn from women who decline vaccination. Public Health Res Pract. 2021; Online early publication. https:// doi.org/10.17061/phrp31232111

\section{Key points}

- Reasons for some pregnant women declining influenza vaccination are infrequently explored and can provide insight into vaccine uptake behaviour during pregnancy

- Pregnant women may not be receiving adequate information on influenza vaccination - in particular, subgroups of women such as those with comorbidities

- A recommendation from maternity care providers remains key to vaccine acceptance; however, pregnant women still lack confidence around vaccine safety and efficacy, highlighting the need for more effective communication

\section{Abstract}

Objective: Pregnant women are recognised as being at risk of serious illness from influenza. Despite this, and longstanding national recommendations for vaccination in pregnancy, vaccine uptake remains suboptimal. This study aims to determine factors associated with women declining influenza vaccination in pregnancy.

Method: We surveyed pregnant women from antenatal clinics at two Sydney hospitals as part of an evaluation of the New South Wales (NSW) Health 2017 influenza vaccination in pregnancy campaign. Factors associated with a woman's decision to decline influenza vaccination were assessed using Pearson's chi-square test and multivariable logistic regression.

Results: Among 642 women surveyed, 58\% self-reported influenza vaccination during pregnancy and $19 \%$ reported they had declined vaccination. Factors associated with a decision to decline vaccination included lack of a recommendation from a maternity care provider (adjusted odds ratio [aOR] 6.06; 95\% confidence interval [Cl] 3.50, 10.50), recommendation against vaccination (aOR 4.17; 95\% Cl 2.07, 8.38), having never previously been vaccinated for influenza (aOR 2.75; 95\% Cl 1.64, 4.59) and, among third-trimester women, not having been vaccinated for pertussis (aOR 2.55; 95\% Cl 1.32, 4.89). On univariate analyses, women who declined vaccination were more likely to disagree or feel uncertain about vaccine safety or effectiveness compared with women who chose to be vaccinated.

Conclusion: Recommendations from maternity care providers remain key to a woman's decision to be vaccinated for influenza during pregnancy. Time should be allocated for vaccine discussions early in pregnancy as part of routine care. Continued efforts are needed to improve messaging to pregnant women on the benefits, safety and efficacy of influenza vaccination. 


\section{Introduction}

Pregnant women are more vulnerable to severe morbidity or mortality from influenza than the general population, including adverse pregnancy outcomes such as congenital abnormalities ${ }^{1}$, premature birth, pregnancy loss and stillbirth. ${ }^{1-3}$ Infants aged less than 6 months, who are too young to be immunised for influenza, are also at high risk of hospitalisation from influenza. 4,5 Influenza vaccination in pregnancy is an essential prevention strategy to protect both mother and infant from influenza and its associated complications.

In Australia, influenza vaccine has been recommended for use in pregnancy by the Australian Technical Advisory Group on Immunisation since 2000. ${ }^{6}$ Since 2010, it has been freely available under the National Immunisation Program for all pregnant women. ${ }^{7}$ Although national data on uptake of the influenza vaccine in pregnancy are lacking, recent estimates of uptake from several Australian states and territories range from 39\% to $76 \%{ }^{8-14}$, suggesting that at least $24 \%$ - and up to $61 \%-$ of pregnant women, do not currently receive the vaccine.

This study aimed to determine factors associated with why pregnant women decline influenza vaccination, to inform program and messaging strategies for improving influenza vaccine uptake in pregnancy.

\section{Methods}

Data for this study were collected as part of an evaluation of the New South Wales (NSW) Health 2017 influenza vaccination in pregnancy campaign. Eligible women were aged older than 18 years, pregnant and English speaking. Recruitment occurred in the waiting rooms of antenatal clinics at two tertiary referral hospitals in Sydney: Westmead Hospital in Sydney's west and Royal North Shore Hospital (RNSH) in Sydney's north, with 5800 and 2800 births, respectively, in $2017 .{ }^{15}$ Women were recruited between July 2017 and September 2017 at Westmead Hospital and between September 2017 and October 2017 at RNSH. Women had the opportunity to be vaccinated after the influenza vaccine became available in late March 2017.

Participants were individually approached and asked to self-complete a paper-based survey that included questions on demographics, self-reported influenza and pertussis vaccination behaviour during their current pregnancy, recommendations received regarding vaccination, access to vaccine-related information and prior history of vaccination. Both women who had declined vaccination and those who had been vaccinated were included in the study. Women who were undecided, stated they were still planning to be vaccinated at the time of the survey or indicated that they were vaccinated before their pregnancy with the same year's vaccine were excluded from analysis. Women who declined vaccination were defined as those who answered "no" to the following question: "Have you had or are you planning to have the flu vaccine during this pregnancy?" They could chooose from the following responses: "No, I would never have it at all", "No, I would never have it while pregnant" and "No, it is too late in the flu season for me to get it". To assess knowledge and perception of influenza and vaccination in pregnancy, survey questions based on Likert scales (strongly agree, agree, neither agree or disagree, disagree, strongly disagree) were used to elicit responses, which were first grouped into three categories (agree, neither agree or disagree, disagree). These categories were further grouped by merging responses for "neither agree or disagree" with other responses to create two categories: 1 - "agree" and 2 - "disagree" for use in regression analysis. Specifically, the "neither agree or disagree" responses were merged with "disagree" responses for questions where the "agree" response supported the statement that spoke to the benefit of vaccination or understanding of the impact of influenza (e.g. "I know what to do if my baby gets the flu"). Similarly, responses to "neither agree or disagree" were merged with "agree" responses where the "disagree" response supported the statement that spoke to the benefit of vaccination or understanding of the impact of influenza (e.g. "Having the flu in pregnancy is not severe"). Women were also asked: "Has anyone said you SHOULD NOT have a flu vaccine in your pregnancy" and could answer from multiple choice: "friend", "family member", "nurse", "midwife", "GP", "obstetrician", "I can't remember" or "other". Data were analysed using STATA (Texas: Stata Corporation; version 15). Descriptive and comparative analyses were performed using Pearson's chi-square or Fisher's exact test, where relevant, with a significance level set at $\alpha=0.05$. Frequency distributions were calculated excluding missing values. Within demographic characteristics, the Index of Relative Socio-Economic Advantage and Disadvantage (IRSAD) for the pregnant woman's area of residence was determined using postcode. IRSAD scores from 1 to 10 were grouped as low (1-4), medium (5-7) and high (8-10). ${ }^{16}$ Study factors (Table 1) were selected for inclusion in regression analysis of women who declined vaccination compared with those who were vaccinated if they correlated with the outcome of interest at a significance level of $p<0.2$ from the Pearson chi-square test. Factors were analysed using backwards stepwise multivariable logistic regression, producing odds ratios and 95\% confidence intervals [Cl]. Variables were retained in the model if they remained statistically significant at $p<0.05$ while adjusting for hospital site.

Participation by both RNSH and Westmead Hospital was approved by the Sydney Children's Hospitals Network Human Research Ethics Committee (LNR/16/ SCHN/275). 


\section{Results}

At Westmead Hospital, 544 women were approached to participate, of whom 354 (65.1\%) completed surveys. At $\mathrm{RNSH}, 308$ women completed surveys; the total number approached was not recorded. Of the 662 women surveyed, 17 (2.6\%) did not provide a response to the question on influenza vaccination in pregnancy, and three women $(0.5 \%)$ were excluded after indicating in free text that they had already been vaccinated before their pregnancy with the same year's vaccine. The remaining 642 women were divided into vaccinated for influenza in current pregnancy $(369 ; 57.5 \%)$, planning to be vaccinated $(77 ; 12.0 \%)$, unaware/undecided $(73 ; 11.4 \%)$ and declined vaccination (123; 19.2\%). Further analysis focused specifically on comparing women who declined vaccination $(n=123)$ with women who had already been vaccinated $(n=369)$.

Characteristics of women who were vaccinated or declined vaccination are outlined in Table 1. Among those who declined vaccination, more women came from Westmead Hospital than from RNSH, and women aged 25-34 years were more likely to be vaccinated $(81.5 \%)$ than older ( $\geq 35$ years; $65.7 \%$ ) and younger (18-24 years; $57.9 \%$ ) women. Women who did not have a tertiary degree and women who reported that it was their first pregnancy were less likely to decline vaccination than women with a tertiary degree or who had previous pregnancies (Table 1).

Table 1. Characteristics and factors among women who declined vaccination or were vaccinated for influenza in their pregnancy $(N=492)$

\begin{tabular}{|c|c|c|c|c|}
\hline Characteristic/factor & $\begin{array}{l}\text { Total } \\
n(\%)\end{array}$ & $\begin{array}{l}\text { Declined } \\
n(\%)\end{array}$ & $\begin{array}{l}\text { Vaccinated } \\
\qquad n(\%)\end{array}$ & $p$ value \\
\hline Total women & $492(100.0)$ & $123(25.0)$ & $369(75.0)$ & \\
\hline \multicolumn{5}{|l|}{ Hospital } \\
\hline Royal North Shore Hospital & $238(48.4)$ & $50(21.0)$ & $188(79.0)$ & \multirow{2}{*}{0.048} \\
\hline Westmead Hospital & $254(51.6)$ & $73(28.7)$ & $181(71.3)$ & \\
\hline \multicolumn{5}{|l|}{ Age, years $(N=491)$} \\
\hline $18-24$ & $38(7.7)$ & $16(42.1)$ & $22(57.9)$ & \multirow{3}{*}{$<0.001$} \\
\hline $25-34$ & $313(63.8)$ & $58(18.5)$ & $255(81.5)$ & \\
\hline 35 and older & $140(28.5)$ & $48(34.3)$ & $92(65.7)$ & \\
\hline \multicolumn{5}{|l|}{ Trimester at time of interview $(N=485)$} \\
\hline Trimester 1 (0-12 weeks) & $8(1.7)$ & $2(25.0)$ & $6(75.0)$ & \multirow{3}{*}{0.576} \\
\hline Trimester 2 (13-26 weeks) & $146(30.1)$ & $41(28.1)$ & $105(71.9)$ & \\
\hline Trimester 3 ( $\geq 27$ weeks) & $331(68.3)$ & $78(23.6)$ & $253(76.4)$ & \\
\hline \multicolumn{5}{|l|}{ Aboriginal and/or Torres Strait Islander $(N=490)$} \\
\hline No & $484(98.8)$ & $122(25.2)$ & $362(74.8)$ & \multirow{2}{*}{1.000} \\
\hline Yes & $6(1.2)$ & $1(16.7)$ & $5(83.3)$ & \\
\hline \multicolumn{5}{|l|}{ Level of education $(N=490)$} \\
\hline Primary or secondary school to year 12 & $57(11.6)$ & $18(31.6)$ & $39(68.4)$ & \multirow{3}{*}{0.034} \\
\hline Trade, apprenticeship, certificate or diploma & $111(22.7)$ & $36(32.4)$ & $75(67.6)$ & \\
\hline Tertiary graduate or postgraduate degree & $322(65.7)$ & $69(21.4)$ & $253(78.6)$ & \\
\hline \multicolumn{5}{|l|}{ Language spoken at home $(N=492)$} \\
\hline English only & $236(48.0)$ & $67(28.4)$ & $169(71.6)$ & \multirow{2}{*}{0.095} \\
\hline Other language(s) & $256(52.1)$ & $56(21.9)$ & $200(78.1)$ & \\
\hline \multicolumn{5}{|l|}{$\begin{array}{l}\text { Index of Relative Socio-economic Advantage and } \\
\text { Disadvantage (IRSAD) }(N=481)\end{array}$} \\
\hline Low (1-4) & $68(14.1)$ & $22(32.4)$ & $46(67.6)$ & \multirow{3}{*}{0.243} \\
\hline Medium (5-7) & $109(22.7)$ & $23(21.1)$ & $86(78.9)$ & \\
\hline High (8-10) & $304(63.2)$ & $76(25.0)$ & $228(75.0)$ & \\
\hline
\end{tabular}


Table 1. Characteristics and factors among women who declined vaccination or were vaccinated for influenza in their pregnancy $(N=492)$ (continued)

\begin{tabular}{|c|c|c|c|c|}
\hline Characteristic/factor & $\begin{array}{l}\text { Total } \\
n(\%)\end{array}$ & $\begin{array}{l}\text { Declined } \\
n(\%)\end{array}$ & $\begin{array}{l}\text { Vaccinated } \\
n(\%)\end{array}$ & $p$ value \\
\hline \multicolumn{5}{|l|}{ Antenatal care $(N=471)$} \\
\hline Primary doctor based at hospital clinic & $298(63.3)$ & $76(25.5)$ & $222(74.5)$ & \multirow{2}{*}{0.563} \\
\hline Shared care: doctor based elsewhere & $173(36.7)$ & $40(23.1)$ & $133(76.9)$ & \\
\hline \multicolumn{5}{|l|}{ Summary of underlying medical conditions ( $N=474)$} \\
\hline No underlying medical conditions & $429(90.5)$ & $106(24.7)$ & $323(75.3)$ & \multirow{2}{*}{0.773} \\
\hline Underlying medical condition & $45(9.5)$ & $12(26.7)$ & $33(73.3)$ & \\
\hline \multicolumn{5}{|l|}{ Underlying medical conditions $(N=45)$} \\
\hline Chronic illness (including diabetes or kidney failure) & $11(24.4)$ & $2(18.2)$ & $9(81.8)$ & \multirow{6}{*}{0.503} \\
\hline Lung disease or asthma & $22(48.9)$ & $7(31.8)$ & $15(68.2)$ & \\
\hline $\begin{array}{l}\text { Chronic neurological condition (including multiple } \\
\text { sclerosis and seizure disorders) }\end{array}$ & $4(8.9)$ & $1(25.0)$ & $3(75.0)$ & \\
\hline $\begin{array}{l}\text { Immune-compromising condition (including HIV } \\
\text { infection) }\end{array}$ & $4(8.9)$ & $0(0)$ & $4(100.0)$ & \\
\hline Heart disease & $1(2.2)$ & $0(0)$ & $1(100.0)$ & \\
\hline Multiple underlying medical conditions & $3(6.7)$ & $2(66.7)$ & $1(33.3)$ & \\
\hline \multicolumn{5}{|l|}{ First pregnancy? $(N=491)$} \\
\hline No & $248(50.5)$ & 72 (29.0) & $176(71.0)$ & \multirow{2}{*}{0.040} \\
\hline Yes & $243(49.5)$ & $51(21.0)$ & $192(79.0)$ & \\
\hline \multicolumn{5}{|l|}{$\begin{array}{l}\text { Maternity care provider recommendation for } \\
\text { vaccination }(N=470)\end{array}$} \\
\hline No & $101(21.5)$ & $52(51.5)$ & $49(48.5)$ & \multirow{2}{*}{$<0.001$} \\
\hline Yes & $369(78.5)$ & $63(17.1)$ & $306(82.9)$ & \\
\hline \multicolumn{5}{|l|}{$\begin{array}{l}\text { Recommendation against influenza vaccination by } \\
\text { anyone }(N=464)\end{array}$} \\
\hline No & $412(88.8)$ & $91(22.1)$ & 321 (77.9) & \multirow{2}{*}{$<0.001$} \\
\hline Yes & $52(11.2)$ & $23(44.2)$ & $29(55.8)$ & \\
\hline \multicolumn{5}{|l|}{$\begin{array}{l}\text { Read information about influenza vaccination } \\
(N=470)\end{array}$} \\
\hline No & $66(14.1)$ & $31(47.0)$ & $35(53.0)$ & \multirow{2}{*}{$<0.001$} \\
\hline Yes & $404(86.0)$ & 86 (21.3) & $318(78.7)$ & \\
\hline \multicolumn{5}{|l|}{$\begin{array}{l}\text { Vaccinated for influenza before this pregnancy (ever) } \\
(N=487)\end{array}$} \\
\hline No & $199(40.9)$ & $69(34.7)$ & $130(65.3)$ & \multirow{2}{*}{$<0.001$} \\
\hline Yes & $288(59.1)$ & 54 (18.8) & $234(81.3)$ & \\
\hline \multicolumn{5}{|l|}{$\begin{array}{l}\text { Vaccinated for influenza in a previous pregnancy } \\
(N=279)\end{array}$} \\
\hline No & $191(68.5)$ & $41(21.5)$ & $150(78.5)$ & \multirow{2}{*}{0.123} \\
\hline Yes & $88(31.5)$ & $11(12.5)$ & 77 (87.5) & \\
\hline \multicolumn{5}{|l|}{$\begin{array}{l}\text { Vaccinated for pertussis in their third trimester } \\
(N=326)\end{array}$} \\
\hline No & $91(27.9)$ & 38 (41.8) & $53(58.2)$ & \multirow{2}{*}{$<0.001$} \\
\hline Yes & $235(72.1)$ & $40(17.0)$ & 195 (83.0) & \\
\hline
\end{tabular}


Table 2. Perceptions of influenza and vaccination among women who declined vaccination or were vaccinated for influenza in their pregnancy $(N=492)^{a}$

\begin{tabular}{|c|c|c|c|c|}
\hline Perceptions & $\begin{array}{l}\text { Total } \\
n(\%)\end{array}$ & $\begin{array}{l}\text { Declined } \\
n(\%)\end{array}$ & $\begin{array}{l}\text { Vaccinated } \\
\qquad n(\%)\end{array}$ & OR $(95 \% \mathrm{Cl})$ \\
\hline \multicolumn{5}{|l|}{$\begin{array}{l}\text { "I know what to do if my baby gets the flu" } \\
(N=462)\end{array}$} \\
\hline $\begin{array}{l}\text { No, I don't agree }(n=75) / \text { Neither agree or } \\
\text { disagree }(n=80)\end{array}$ & $155(33.6)$ & 35 (22.6) & $120(77.4)$ & referent \\
\hline Yes, I agree & 307 (66.5) & $83(27.0)$ & 224 (73.0) & $1.27(0.81,2.00)$ \\
\hline \multicolumn{5}{|l|}{$\begin{array}{l}\text { "The flu vaccine is safe for pregnant women to } \\
\text { have" }(N=469)\end{array}$} \\
\hline $\begin{array}{l}\text { No, I don't agree }(n=23) / \text { Neither agree or } \\
\text { disagree }(n=68)\end{array}$ & $91(19.4)$ & $63(69.2)$ & $28(30.8)$ & $13.21(7.78,22.43)$ \\
\hline Yes, I agree & $378(80.6)$ & 55 (14.6) & 323 (85.5) & referent \\
\hline
\end{tabular}

"I know the symptoms of the flu" $(N=454)$

No, I don't agree $(n=22) /$ Neither agree or disagree $(n=29)$

Yes, I agree

$403(88.8)$

$103(25.6)$

$300(74.4)$

$1.12(0.56,2.21)$

"The flu vaccine in pregnancy is dangerous for the baby" $(N=463)$

No, I don't agree $309(66.7)$ $45(14.6)$ $264(85.4)$

referent

Yes, I agree $(n=49) /$ Neither agree or disagree $(n=105)$

154 (33.3)

$72(46.8)$

$82(53.3)$

$5.15(3.29,8.06)$

"Having the flu vaccine in my pregnancy will protect me from the flu" $(N=468)$

No, I don't agree $(n=56) /$ Neither agree or disagree $(n=104)$

$160(34.2)$

$308(65.8)$

Yes, I agree

"Having the flu vaccine in my pregnancy won't protect my baby once he/she is born" $(N=465)$

No, I don't agree $162(34.8)$

$144(88.9)$

referent

Yes, I agree $(n=101) /$ Neither agree or disagree $(n=202)$

$303(65.2)$

$99(32.7)$

$204(67.3)$

$3.88(2.25,6.70)$ protect my baby during my pregnancy" $(N=465)$

No, I don't agree $(n=31) /$ Neither agree or disagree $(n=146)$

$177(38.1)$

$288(61.9)$

"Having the flu in pregnancy is not severe"

$(N=459)$

No, I don't agree

$50(19.8)$

$206(44.9)$ $(n=131)$
$203(80.2)$

$144(69.9)$
$7.95(4.92,12.83)$

referent

referent

$1.75(1.14,2.69)$

a Not all women answered each question, as demonstrated by the different ' $N$ ' values shown for each category.

$\mathrm{Cl}=$ confidence interval; $\mathrm{OR}=$ odds ratio 
Further, vaccination was declined by $51.5 \%$ of women who did not receive a recommendation from a maternity care provider to have an influenza vaccination, $44.2 \%$ of women who received a recommendation from anyone not to have the vaccine, $47.0 \%$ of women who had not read information on influenza vaccination in pregnancy, $34.7 \%$ of women who had not been previously vaccinated for influenza and $41.8 \%$ of women in their third trimester who had not yet received the pertussis vaccine in their pregnancy (Table 1).

Among the 52 women who reported that they were recommended against vaccination by anyone, four $(7.7 \%)$ reported the recommendations were from a healthcare provider: two from general practitioners (GPs), one from a midwife and one from a obstetrician. Three of those participants declined vaccination. One woman who received a recommendation aganst vaccination by her obsterician reported it was due to a "previous bad reaction to the influenza vaccine". There were no reasons specified as to why the two GPs recommended against vaccination and both women declined vaccination in those cases, although one reported also receiving a recommendation against vaccination from family and friends. The woman who received a recommendation against vaccination from a midwife went on to get vaccinated. In addition, there were 37 women who reported that family or friends provided a recommendation against vaccination and a further 11 women reported the source of a recommendation against vaccination as either "other" $(n=6)$ or "I can't remember/no answer" ( $n=5)$.

Responses to questions around vaccine safety revealed that $69.2 \%$ of women who disagreed or neither agreed/disagreed that "the flu vaccine is safe for pregnant women to have" and $46.8 \%$ of women who agreed or neither agreed/disagreed "the flu vaccine in pregnancy is dangerous for the baby" had declined vaccination (Table 2). Responses to questions around vaccine effectiveness revealed that vaccination was declined by $48.8 \%$ of women who disagreed or neither agreed/disagreed that "having the flu vaccine in my pregnancy will protect me from the flu", 32.7\% of women who agreed or neither agreed/disagreed that "having the flu vaccine in my pregnancy won't protect my baby once he/she is born" and $48.0 \%$ of women who disagreed or neither agreed/disagreed that "having the flu vaccine in my pregnancy will protect my baby during my pregnancy" (Table 2). Because of high collinearity among perception variables, and of perception variables with a maternity care provider recommendation, perception variables were not included in subsequent multivariable modelling. Odds ratios from univariate analyses are shown in Table 2.

Among the 45 women who reported an underlying medical condition, 12 (26.7\%) declined vaccination, of whom five $(41.7 \%)$ had received a recommendation to have the vaccine from a maternity care provider (Table 3). Seven women with an underlying medical condition received conflicting recommendations, of whom three (42.9\%) declined vaccination (Table 3).

Table 4 outlines factors analysed using multivariable analysis for their association with a pregnant woman's decision to decline vaccination. After adjustment, significant factors included lack of a maternity care provider recommendation for vaccination; having been recommended against vaccination by anyone; not ever having been previously vaccinated for influenza; and, among third-trimester women, not having received the pertussis vaccine in their pregnancy. There was no significant difference between hospitals in the adjusted model (Table 4). Trimester of pregnancy was not included in the model on the basis that the proportion of women who declined was similar for each trimester group and was not a significant factor. Having read information on influenza vaccination was also highly collinear with having received a maternity care provider recommendation and was excluded from the model.

Among women who declined vaccination and who had received a maternity care provider recommendation, 83.3\% (50/60) acknowledged having read information on influenza vaccination in pregnancy. Of these, 38/50

Table 3. Vaccine recommendations among pregnant women with an underlying medical condition $(N=45)^{\mathrm{a}}$

\begin{tabular}{|c|c|c|c|c|}
\hline Recommendations & $\begin{array}{l}\text { Total } \\
n(\%)\end{array}$ & $\begin{array}{l}\text { Declined } \\
n(\%)\end{array}$ & $\begin{array}{l}\text { Vaccinated } \\
\qquad n(\%)\end{array}$ & $p$ value \\
\hline Total women & $45(100)$ & $12(26.7)$ & $33(73.3)$ & \\
\hline MCP recommendation for vaccination & $28(62.2)$ & $2(7.1)$ & $26(92.9)$ & \\
\hline $\begin{array}{l}\text { MCP recommendation for vaccination } \\
\text { and recommendation against } \\
\text { vaccination by anyone }\end{array}$ & $7(15.6)$ & $3(42.9)$ & $4(57.1)$ & $<0.001$ \\
\hline $\begin{array}{l}\text { Recommendation against vaccination } \\
\text { by anyone }\end{array}$ & $2(4.4)$ & $1(50.0)$ & $1(50.0)$ & \\
\hline $\begin{array}{l}\text { No recommendations for or against } \\
\text { vaccination }\end{array}$ & $8(17.8)$ & $6(75.0)$ & $2(25.0)$ & \\
\hline
\end{tabular}


Table 4. Multivariable logistic regression analysis of factors associated with a woman's decision to decline influenza vaccination $(N=492)$

\begin{tabular}{|c|c|c|}
\hline Study factor & Univariate analysis: OR $(95 \% \mathrm{Cl})$ & $\begin{array}{l}\text { Multivariable analysis: aOR }(95 \% \mathrm{Cl}) \\
\qquad N=451^{\mathrm{a}}\end{array}$ \\
\hline \multicolumn{3}{|l|}{ Site $(N=492)$} \\
\hline Royal North Shore Hospital & referent & referent \\
\hline Westmead Hospital & $1.52(1.00,2.29)$ & $1.18(0.72,1.97)$ \\
\hline \multicolumn{3}{|l|}{ Age, years $(N=491)$} \\
\hline $18-24$ & referent & referent \\
\hline $25-34$ & $0.31(0.15,0.63)$ & $0.35(0.15,0.83)$ \\
\hline 35 and older & $0.72(0.34,1.49)$ & $1.01(0.41,2.51)$ \\
\hline \multicolumn{3}{|l|}{ Education $(N=490)$} \\
\hline Primary or secondary school to year 12 & $1.69(0.91,3.14)$ & - \\
\hline Trade, apprenticeship, certificate or diploma & $1.76(1.09,2.84)$ & - \\
\hline Tertiary graduate or postgraduate degree & referent & - \\
\hline \multicolumn{3}{|l|}{$\begin{array}{l}\text { Language other than English at home (not } \\
\text { exclusive of English) }(N=492)\end{array}$} \\
\hline No & referent & - \\
\hline Yes & $0.71(0.47,1.06)$ & - \\
\hline \multicolumn{3}{|l|}{ First pregnancy $(N=491)$} \\
\hline No & $1.54(1.02,2.33)$ & - \\
\hline Yes & referent & - \\
\hline \multicolumn{3}{|l|}{ MCP recommendation $N=470$ ) } \\
\hline No & $5.15(3.20,8.29)$ & $6.06(3.50,10.50)$ \\
\hline Yes & referent & referent \\
\hline \multicolumn{3}{|l|}{$\begin{array}{l}\text { Recommended against influenza vaccination } \\
\text { by anyone }(N=464)\end{array}$} \\
\hline No & referent & referent \\
\hline Yes & $2.80(1.54 .5 .07)$ & $4.17(2.07,8.38)$ \\
\hline \multicolumn{3}{|l|}{$\begin{array}{l}\text { Vaccinated for influenza before this } \\
\text { pregnancy (ever) }(N=487)\end{array}$} \\
\hline No & $2.30(1.52,3.49)$ & $2.75(1.64,4.59)$ \\
\hline Yes & referent & referent \\
\hline \multicolumn{3}{|l|}{$\begin{array}{l}\text { Vaccinated for pertussis (third-trimester } \\
\text { women) }(N=492)\end{array}$} \\
\hline No & $3.50(2.04,5.99)$ & $2.55(1.32,4.89)$ \\
\hline Yes & referent & referent \\
\hline Missing ( $n=166$, not third trimester) & $1.81(1.12,2.94)$ & $1.78(1.00,3.16)$ \\
\hline
\end{tabular}

a $N=451$ due to several covariates having some missing data in the final model.

$-=$ variable not included in final model where $p>0.2$ ( $p$ value not shown), except for site; aOR = adjusted odds ratio; $\mathrm{Cl}=\mathrm{confidence} \mathrm{interval;}$ $\mathrm{MCP}=$ maternity care provider; $\mathrm{aOR}=$ adjusted odds ratio

(76.0\%) had read a brochure and 28/50 (56.0\%) referred to the internet (responses were not mutually exclusive).

\section{Discussion}

This study identified multiple factors potentially contributing to a woman's decision to decline influenza vaccination in pregnancy. We demonstrated that the absence of a maternity care provider recommendation increased the odds of declining vaccination in pregnancy by more than six times. These findings are consistent with other Australian studies in which maternity care provider recommendations have consistently been shown to improve influenza vaccine uptake among 
pregnant women. ${ }^{10-12,17}$ Reading information on influenza vaccination in pregnancy, such as supplementary brochures, social media and mobile phone apps, may also be successful in increasing exposure to messaging about the benefits of vaccination in pregnancy. ${ }^{9}$ Women who declined vaccination were strongly influenced not to be vaccinated, primarily by family or friends. When a woman openly declines a vaccination in her pregnancy, it may be beneficial for a maternity care provider to ask if the woman has received a personal recommendation against vaccination and attempt to address any myths or misconceptions she may have been exposed to.

On unadjusted univariate analysis, strong concerns about vaccine safety in pregnancy for both mother and baby were evident; women who declined vaccination were 13 times more likely to disagree or neither agree or disagree that influenza vaccination was safe for pregnant women than those who were vaccinated. Further, 62\% of women who declined vaccination agreed, or neither agreed or disagreed, that influenza vaccination in pregnancy was dangerous for the baby, compared with only $24 \%$ of women who were vaccinated. Concerns about vaccine safety have frequently been reported in other studies as one of the main reasons for hesitancy or not vaccinating for influenza during pregnancy. ${ }^{9,10,18-20}$

Poor perceptions of vaccine effectiveness were also evident among pregnant women who declined vaccination. Women were 6-8 times more likely to decline vaccination if they did not agree that the influenza vaccine would protect either themselves or their baby during pregnancy. Also, $85 \%$ of women who declined vaccination and $59 \%$ of women who were vaccinated agreed, or neither agreed or disagreed, that the flu vaccine would not protect their baby once born. Although women who declined vaccination were more likely to hold this view, it is also apparent that there is a substantial lack of confidence in vaccine effectiveness among all women regarding the protection of newborns. A lack of confidence in the effectiveness of the influenza vaccine among pregnant women, in general, was also reported from the earlier NSW pilot study ${ }^{9}$, and from a study in the UK. ${ }^{21}$ Therefore, clearer, evidence-based messaging of the risks versus benefits of vaccination in pregnancy during antenatal visits is likely to increase the effectiveness of vaccine recommendations.

Among pregnant women in their third trimester, women who had not yet received antenatal pertussis vaccination were 2.5 times more likely to decline influenza vaccination than those who had received pertussis vaccination. Communicating about pertussis and influenza vaccinations in pregnancy simultaneously and as part of routine antenatal care may help to improve acceptance of both vaccinations. The opportunity may arise more frequently in future because the recommendation for timing of pertussis vaccination in Australia has been revised down from 28 weeks to 20 weeks gestation. ${ }^{6}$ An approach using standing orders for maternal vaccination, whereby a midwife is able to administer an antenatal vaccine after obtaining informed consent, and without the need of a medical order ${ }^{22}$, can also support the needs of a maternity care provider who may have different priorities for antenatal care. ${ }^{23}$ In Australia, use of standing orders during midwifery-led antenatal clinic appointments has seen pertussis vaccine uptake in pregnancy improve to $90 \%$, and influenza vaccine uptake increase to 83 $91 \% .{ }^{11,22}$

Among women with an underlying medical condition who either declined to be vaccinated or were vaccinated, we found that $22 \%$ did not receive a recommendation to receive the influenza vaccine from their maternity care provider. Pregnant women are already an identified group at high risk of serious complications from influenza illness and are therefore potentially at greater risk when they have underlying comorbidities. ${ }^{6}$ These women are likely to require more antenatal care appointments; however, despite an increased number of consultations, time to discuss vaccination may still be limited as attention is focused primarily on the care of the mother and her pregnancy under complex circumstances. Therefore, it remains especially important for the maternity care provider to discuss vaccination in the context of her heightened risks.

\section{Strengths and limitations}

Our study is one of few to highlight issues of vaccine uptake specifically among women who declined vaccination during their pregnancy and to report on women with underlying medical conditions. There are, however, several limitations to this study. We were not able to consistently validate receipt of influenza vaccination by checking patient- or provider-held records, although prior research has indicated vaccine recall during pregnancy to be highly reliable. ${ }^{24}$ Also, as the survey was conducted while women were pregnant, it is possible that some women who declined vaccination may have subsequently decided to get vaccinated. Women surveyed later in the influenza season may be more likely to feel that it is too late for vaccination; however, less than $1 \%$ of women surveyed later in the season were in their first trimester, indicating ample opportunity for women surveyed in their second or third trimester to have already been vaccinated.

Although we surveyed women from two geographically distinct areas within Sydney, women surveyed may not be truly representative of the broader population in NSW. For instance, in NSW, $24.7 \%$ of women who gave birth in 2017 were aged older than 35 years $^{15}$, compared with $28.5 \%$ in our study. The $1.2 \%$ of respondents in our study who were Aboriginal or Torres Strait Islander was substantially lower than the reported $4.4 \%$ of Indigenous births reported in NSW for $2017 .{ }^{15}$ Both hospitals had a significant proportion of women who spoke at least one language other than English at home, but resources did not permit interview of women not fluent in English, limiting our ability to assess data from women of culturally 
and linguistically diverse backgrounds. Many women receiving care through a private obstetrician would also not have been captured and thus would not be well represented in this study.

\section{Conclusion}

Multiple factors can influence a pregnant woman's decision to decline influenza vaccination. The absence of a recommendation for vaccination from a maternity care provider is central to this decision. Time should be allocated for discussions around both influenza and pertussis vaccination, ideally early in pregnancy, and these discussions should be integrated as part of routine antenatal care. Particular attention should be paid to women with underlying medical conditions during vaccine discussions. Finally, continued effort is needed to improve messaging on the benefits, safety and effectiveness of influenza vaccination, for protection of the pregnant woman, developing baby and newborn.

\section{Acknowledgements}

The authors acknowledge the support of Kathy Gordon, Nurse Unit Manager, Women's and Newborn Health Clinic at Westmead Hospital; Kathryn Meredith, Research Nurse and Dr Helen Quinn, Senior Research Fellow, National Centre for Immunisation Research and Surveillance; staff at the Women's and Newborn Health Clinic at Westmead Hospital; and Professor Michael Nicholl, Head of Department, Yan Chen, Research Nurse, and staff at Women's, Children's and Family Health, Royal North Shore Hospital.

\section{Peer review and provenance}

Externally peer reviewed, not commissioned.

\section{Competing interests}

None declared.

\section{Author contributions}

The study was planned and designed by AD, FB, KM, SC, JS, NW and JM. Data analysis was performed by JM, and $A D, F B, K M, P M$ and NW assisted with data interpretation. $\mathrm{JM}$ prepared the first draft of the manuscript under guidance from NW. All authors read and contributed to subsequent drafts and approved the final manuscript.

\section{References}

1. Somerville LK, Basile K, Dwyer DE, Kok J. The impact of influenza virus infection in pregnancy. Future Microbiol. 2018;13(2):263-74.
2. Rasmussen SA, Jamieson DJ, Uyeki TM. Effects of influenza on pregnant women and infants. Am J Obstet Gynecol. 2012;207(3 SUPPL.):S3-S8.

3. Fell DB, Azziz-Baumgartner E, Baker MG, Batra M, Beauté J, Beutels $P$, et al. Influenza epidemiology and immunization during pregnancy: final report of a World Health Organization working group. Vaccine. 2017;35(43):5738-50.

4. Li-Kim-Moy J, Yin JK, Blyth CC, Kesson A, Booy R, Cheng AC, Macartney K. Influenza hospitalizations in Australian children. Epidemiol Infect. 2017; 145(7):1451-60.

5. Fell DB, Johnson J, Mor Z, Katz MA, Skidmore B, Neuzil KM, et al. Incidence of laboratory-confirmed influenza disease among infants under 6 months of age: a systematic review. BMJ Open. 2017;7(9):e016526.

6. Australian Technical Advisory Group on Immunisation (ATAGI). Australian Immunisation Handbook. Canberra: Australian Government Department of Health; 2018 [cited 2021 May 28]. Available from: immunisationhandbook. health.gov.au

7. National Centre for Immunisation Research and Surveillance. Significant events in influenza vaccination practice in Australia. Sydney: NCIRS; 2018 [cited 2021 Jun 17]. Available from: www.ncirs.org.au/healthprofessionals/history-immunisation-australia

8. Danchin $\mathrm{MH}$, Costa-pinto J, Attwell $\mathrm{K}$, Willaby $\mathrm{H}$, Wiley $\mathrm{K}, \mathrm{Hoq} \mathrm{M}$, et al. Vaccine decision-making begins in pregnancy: correlation between vaccine concerns, intentions and maternal vaccination with subsequent childhood vaccine uptake. Vaccine. 2018;36(44):6473-79.

9. Carlson S, Dey A, Beard F. An evaluation of the 2016 influenza vaccination in pregnancy campaign in NSW, Australia. Public Health Res Pract. 2020;30(1):29121908.

10. Mak DB, Regan AK, Vo DT, Effler P V. Antenatal influenza and pertussis vaccination in Western Australia: a crosssectional survey of vaccine uptake and influencing factors. BMC Pregnancy Childbirth. 2018;18(1):416.

11. Mohammed H, Clarke M, Koehler A, Watson M, Marshall $\mathrm{H}$. Factors associated with uptake of influenza and pertussis vaccines among pregnant women in South Australia. PLoS One. 2018;13(6):e0197867.

12. Krishnaswamy S, Cheng AC, Wallace EM, Buttery J, Giles ML. Understanding the barriers to uptake of antenatal vaccination by women from culturally and linguistically diverse backgrounds: a cross-sectional study. Hum Vaccin Immunother. 2018;14(7):1591-98.

13. Rowe SL, Perrett KP, Morey R, Stephens N, Cowie B, Nolan TM, et al. Influenza and pertussis vaccination of women during pregnancy in Victoria, 2015-2017. Med J Aust. 2019:201(10):454-62. 
14. Overton K, Webby R, Markey P, Krause V. Influenza and pertussis vaccination coverage in pregnant women in the Northern Territory in 2015-new recommendations to be assessed. North Territ Dis Control Bull. 2016;23(4):1-7.

15. Centre for Epidemiology and Evidence. New South Wales Mothers and Babies 2017. Sydney: NSW Ministry of Health; 2018 [cited 2021 May 28]. Available from: www. health.nsw.gov.au/hsnsw/Publications/mothers-andbabies-2017.pdf

16. Australian Bureau of Statistics. Census of population and housing: Socio-Economic Indexes for Areas (SEIFA), Australia, 2016. IRSAD. Canberra: ABS; 2018 [cited 2018 Nov 28]. Available from: www.abs.gov.au/ausstats/ abs@.nsf/Lookup/by Subject/2033.0.55.001 2016 Main Features IRSAD 20

17. Maher L, Hope K, Torvaldsen S, Lawrence G, Dawson A, Wiley $\mathrm{K}$, et al. Influenza vaccination during pregnancy: coverage rates and influencing factors in two urban districts in Sydney. Vaccine. 2013;31(47):5557-64.

18. Wilson RJ, Paterson P, Jarrett C, Larson HJ. Understanding factors influencing vaccination acceptance during pregnancy globally: a literature review. Vaccine. 2015;33:6420-9.

19. Yuen CY, Tarrant M. Determinants of uptake of influenza vaccination among pregnant women - a systematic review. Vaccine. 2014;32(36):4602-13.
20. Kilich E, Dada S, Francis MR, Tazare J, Chico RM, Paterson $\mathrm{P}$, et al. Factors that influence vaccination decision-making among pregnant women: a systematic review and meta-analysis. PLoS One. 2020;15(7):e0234827.

21. Wilcox CR, Calvert A, Metz J, Kilich E, MacLeod R, Beadon K, et al. Determinants of influenza and pertussis vaccination uptake in pregnancy: a multi-centre questionnaire study of pregnant women and healthcare professionals. Pediatr Infect Dis J. 2019;38(6):625-30.

22. Krishnaswamy S, Wallace EM, Buttery J, Giles ML. Strategies to implement maternal vaccination: a comparison between standing orders for midwife delivery, a hospital based maternal immunisation service and primary care. Vaccine. 2018;36(13):1796-800.

23. Ellingson MK, Dudley MZ, Limaye RJ, Salmon DA, O'Leary ST, Omer SB. Enhancing uptake of influenza maternal vaccine. Expert Rev Vaccines. 2019;18(2):191-204.

24. Regan AK, Mak DB, Hauck YL, Gibbs R, Tracey L, Effler $P$ V. Trends in seasonal influenza vaccine uptake during pregnancy in Western Australia: implications for midwives. Women Birth. 2016;29(5):423-29.

\section{Copyright: (c) (i) (-) (-)}

(C) $2021 \mathrm{McCrae}$ et al. This article is licensed under the Creative Commons Attribution-NonCommercial-ShareAlike 4.0 International Licence, which allows others to redistribute, adapt and share this work non-commercially provided they attribute the work and any adapted version of it is distributed under the same Creative Commons licence terms. See: www.creativecommons.org/licenses/by-nc-sa/4.0/ 